\title{
INTERACTION OF HYDROGEN WITH DEFORMED METAL
}

\author{
A.P. PALTSEVICH, V.S. SINYUK and A.V. IGNATENKO \\ E.O. Paton Electric Welding Institute, NASU
}

11 Bozhenko Str., 03680, Kiev, Ukraine. E-mail: office@paton.kiev.ua

\begin{abstract}
This work investigates the peculiarities of formation of residual hydrogen as a result of plastic strain of metal, containing diffusible hydrogen. Characteristic of this process is increase of content of hydrogen trapped by dislocations, $[\mathrm{H}]_{\text {def. }}$. It is testified by appearance of a peak in thermodesorption spectrum with maximum rate of removal at $150-170{ }^{\circ} \mathrm{C}$ as well as rise of $[\mathrm{H}]_{\text {def }}$ at increase of plastic strain level. Also, it was experimentally showed that $[\mathrm{H}]_{\text {def }}$ reduces after long period of storage of deformed specimens at room temperature. This confirms reversible nature of dislocations as hydrogen traps. A value of hydrogen diffusion coefficient in the plastically deformed weld metal is determined by interaction of hydrogen with dislocations and being 3 orders lower than for the undeformed metal. The experiments showed that rise of metal strength provides for reduction of value of plastic strain, at which fracture takes place, under effect of diffusible hydrogen. At that, content of $[\mathrm{H}]_{\text {def }}$ in the moment of fracture also significantly decreases with increase of metal strength. 12 Ref., 3 Tables, 5 Figures.
\end{abstract}

Keywords: diffusible hydrogen, residual hydrogen, deformation-trapped hydrogen, plastic strain, hydrogen thermodesorption analysis

Behavior of hydrogen in metals is considered as a rule from point of view of its solubility, diffusion and interaction with structure defects [1, $2]$. One of the irregularities of crystalline structure of metal of welds and steels is the dislocations, representing itself linear defects of crystalline structure [3, 4]. Annealed crystals contain from $10^{4}$ to $10^{6}$ dislocations per $1 \mathrm{~cm}^{2}$. Plastic strain of crystalline materials is carried out by nucleation and movement of the dislocations, at that their density rises to $10^{10}-10^{12} \mathrm{~cm}^{-2}$ [5]. Fixing and redistribution of the interstitial atoms (hydrogen, carbon and nitrogen), among which hydrogen has the lowest bonding energy and the highest diffusion coefficient [3,6-8], take place in iron and steels under effect of the stress dislocation fields. Therefore, hydrogen is fixed first on the «fresh» dislocations [8] formed as a result of plastic strain.

Absorption of hydrogen by weld pool metal takes place in arc welding of steels. Prevention of cold crack formation [9] is a relevant problem for high-strength steels. A mechanism of crack formation in many respects is related to interaction of hydrogen with dislocation structure of weld metal and near-weld zone, caused by thermo-deformation welding cycle. At the same time, level of experimental data, indicating typical peculiarities of the interaction of hydrogen with dislocations in steels and welds, is not enough, regardless the presence of theoretical backgrounds of interaction of hydrogen with dislocation and its role in formation of the cold cracks. Therefore, present work is dedicated to investigation of the interaction of hydrogen with plastically deformed weld metal.

VSt3sp (killed) steel as well as weld metal, produced by single-pass welding using low-hydrogen electrodes UONI-13/55 and pilot electrodes IP (Table 1), were used as material for investigations.

Determination of effect of the cold plastic strain on behavior of hydrogen in metal of single-pass weld was carried out by means of comparison of its condition in relation to residual hydrogen after removal of $[\mathrm{H}]_{\text {dif }}$ in deformed and undeformed specimens. Deforming of the speci-

Table 1. Chemical composition of investigated materials, wt.\%

\begin{tabular}{||l|c|c|c|c|c|c|c|c|c|c|c||}
\hline \multicolumn{1}{|c|}{ Material } & $\mathrm{C}$ & $\mathrm{Si}$ & $\mathrm{Mn}$ & $\mathrm{S}$ & $\mathrm{P}$ & $\mathrm{Cr}$ & $\mathrm{Ni}$ & $\mathrm{Ti}$ & $\mathrm{Mo}$ & $\mathrm{V}$ & $\mathrm{Al}$ \\
\hline Steel VSt3sp & 0.12 & 0.139 & 0.37 & 0.022 & 0.012 & 0.12 & 0.10 & - & - & - & - \\
\hline Weld metal (UONI-13/55)* & 0.062 & 0.274 & 0.96 & 0.008 & 0.0019 & - & - & 0.024 & - & - & - \\
\hline Weld metal (IP) & 0.04 & 0.270 & 0.98 & 0.007 & 0.015 & 0.88 & 2.36 & 0.005 & 0.45 & 0.18 & 0.007 \\
\hline
\end{tabular}

*Chemical composition was determined by spectral analysis on multilayer deposit. 


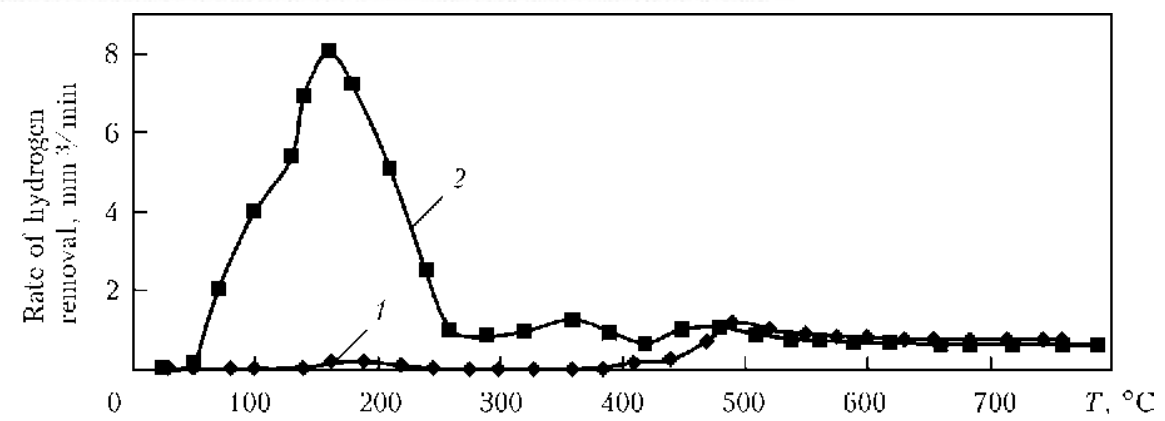

Figure 1. Thermodesorption of residual hydrogen from deformed and undeformed weld metal: 1 - specimen without deformation; 2 - specimen with $6 \%$ deformation

mens in clamps with water-cooled jaws was carried out using bending in mandrel for $2-5 \mathrm{~min}$ after cooling in water. The specimens represent themselves a weld bead deposited on workpiece of $10 \times 15 \times 45 \mathrm{~mm}$ size. A value of plastic strain in central part of the weld was set by mandrel curvature radius. Specimens of $15 \times 4 \times 1 \mathrm{~mm}$ size were cut out from upper part of the deposited metal after holding during 5 days at room temperature. Measurement of content of the residual hydrogen was carried out with the help of thermodesorption analysis (TDA) [10]. It was improved for measurement of content of fractions of hydrogen in metal, emitted in process of heating to $900{ }^{\circ} \mathrm{C}$ with regulated speed, which made $5{ }^{\circ} \mathrm{C} / \mathrm{min}$ during analysis.

Figure 1 represents the results of TDA of undeformed weld metal and $6 \%$ bending deformed weld metal, which were deposited using IP electrodes (see Table 1). Given data show that the residual hydrogen, which starts to remove at reaching of temperature around $500{ }^{\circ} \mathrm{C}$, is present in TDA spectrum of the both specimens. Presence of $[\mathrm{H}]_{\mathrm{def}}$ peak with maximum temperature of $150-170{ }^{\circ} \mathrm{C}$ is typical for the deformed specimen. The reason of its appearance is connection of hydrogen with dislocation structure of the deformed metal, from which it is removed by heating. The same peak of hydrogen was received in work [11] in TDA of pure iron after thermal saturation,

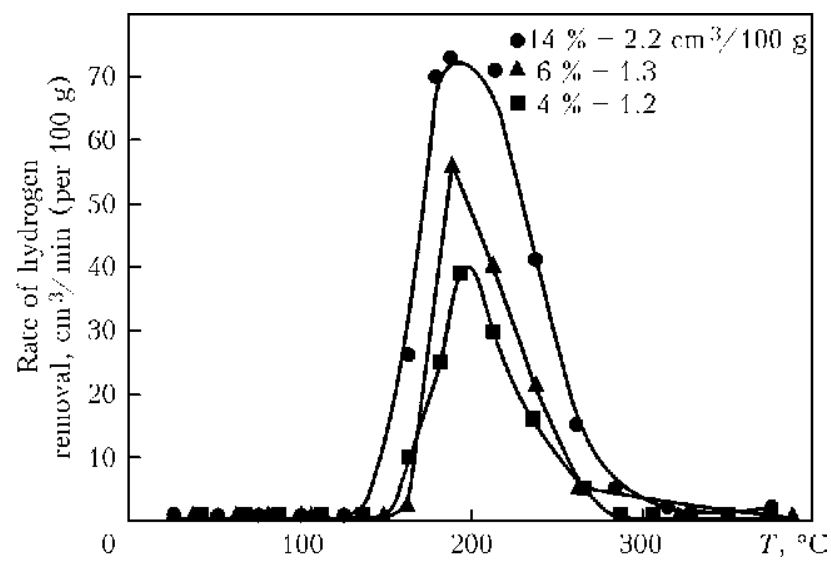

Figure 2. Effect of level of plastic strain on $[\mathrm{H}]_{\mathrm{def}}$ content cold plastic strain and removal of diffusible hydrogen.

Figure 2 shows effect of the level of plastic strain of single-pass weld metal, produced by UONI-13/55 electrodes, on redistribution of hydrogen. It can be seen on presented data that reduction of the level of plastic strain decreases hydrogen concentration in the deformed metal $[\mathrm{H}]_{\text {def }}$.

Dislocations are referred to the reversible hydrogen traps due to low bonding energy [3, 6 , 7]. In this case desorption of the diffusible hydrogen from specimen should promote transfer of hydrogen, kept by the dislocations, into crystalline lattice and, thus, reduction of $[\mathrm{H}]_{\text {def }}$ concentration. For verification of reduction of $[\mathrm{H}]_{\mathrm{def}}$ concentration a series of welded specimens, produced by UONI-13/55 electrodes, was deformed by $6 \%$ and kept in laboratory at $T=16-25{ }^{\circ} \mathrm{C}$. Specimens for performance of TDA and determination of $[\mathrm{H}]_{\mathrm{def}}$ concentration were cut out from the welded joints within time intervals, indicated in Figure 3. Reduction of hydrogen concentration from 1.4 to $0.2 \mathrm{~cm}^{3} / 100 \mathrm{~g}$ is observed in the deformed welds after long period of time. The peculiarity of such decrease is shifting of the maximum of $[\mathrm{H}]_{\text {def }}$ removal peak from 120 to $170{ }^{\circ} \mathrm{C}$. Thus, removal of hydrogen from dislocation structure of the deformed metal takes place at room temperature.

Investigations of effect of plastic strain on hydrogen diffusion at room temperature were carried out using cylinder specimens, received by sampling of metal from the weld pool into quartz tube during welding by $5 \mathrm{~mm}$ diameter UONI$13 / 55$ electrodes. Initial specimen of $4.8 \mathrm{~mm}$ diameter and $15 \mathrm{~mm}$ length was deformed by flatting (deformation around $30 \%$ ) and turned to cylinder shape. The experiments were performed with the help of chamber allowing collection of emitted hydrogen from the specimen approximately during $16 \mathrm{~h}$ for one measurement cycle. This permitted to increase measurement sensitivity. Figure 4 shows the kinetics of removal of hydrogen at room temperature for the deformed and undeformed metal. 


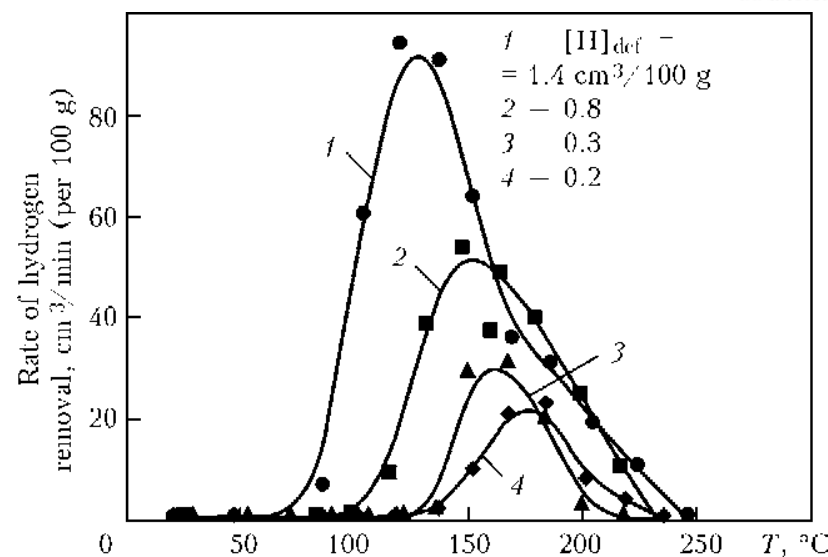

Figure 3. Thermodesorption of hydrogen from welded specimens: 1 - after $5 ; 2-64 ; 3-95 ; 4-124$ days

TDA of the specimens after end of the stage of measurement of hydrogen removal kinetics showed presence of $[\mathrm{H}]_{\text {def }}$ in the deformed specimen in the amount of $0.6 \mathrm{ml} / 100 \mathrm{~g}$ with maximum removal rate at $T=150{ }^{\circ} \mathrm{C}$, and absent of $[\mathrm{H}]_{\text {def }}$ in the undeformed specimen. Virtually all hydrogen in plastically deformed metal is trapped with the dislocation structure. In order that the hydrogen atom can escape from the metal, it firstly should break the energy barrier and detach from the dislocation holding it. Therefore, value of diffusion coefficient in the deformed metal is determined by interaction of hydrogen with dislocations and makes $3.2 \cdot 10^{-8} \mathrm{~cm}^{2} / \mathrm{s}$. Value of effective diffusion coefficient for the undeformed metal in the beginning of degassing makes $10^{-5} \mathrm{~cm}^{2} / \mathrm{s}$, and this value gradually decreases to $3 \cdot 10^{-8} \mathrm{~cm}^{2} / \mathrm{s}$ after removal of $90 \%$ of diffusible hydrogen.

Effect of hydrogen on fracture of steel VSt3sp and weld metal, produced by relemting of pilot electrode IP in copper water-cooled mould, was determined by uniaxial tensile tests of preliminary hydrogen-charged specimens using servohydraulic machine INSTRON-1251 at deformation rate $10^{-3} \mathrm{~s}^{-1}$. Hydrogen saturation of the specimens was electrolytic in $5 \%$ solution of sulfuric acid with $0.05 \%$ addition of sodium thiosulfate at current density of $10 \mathrm{~mA} / \mathrm{cm}^{2}$ during $4 \mathrm{~h}$. Table 2 shows the results of mechanical tests. $[\mathrm{H}]_{\text {dif }}$ was removed from the fractured specimens at room temperature during 5 days after mechanical tests, and then TDA was carried out ( $\mathrm{Fi}_{-}$ gure 5). It can be seen based on given data that

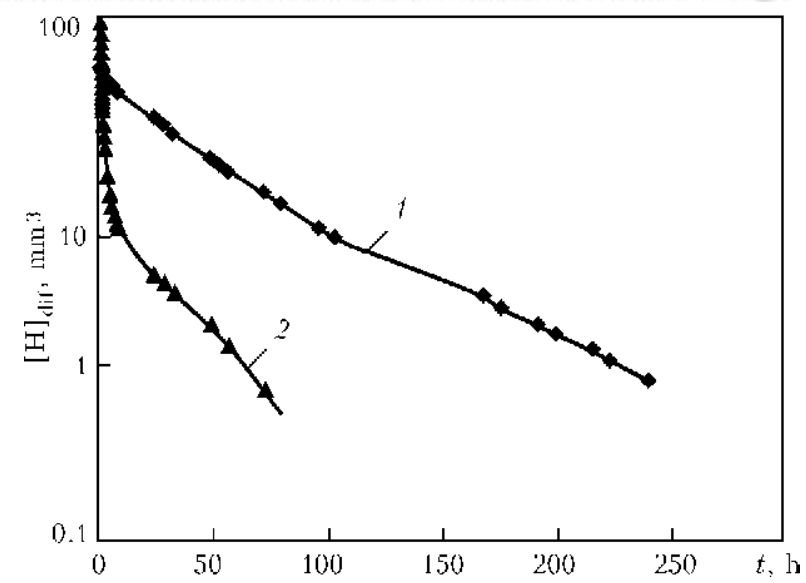

Figure 4. Kinetics of hydrogen removal from deformed (1) and undeformed (2) specimens

fracture of metal of high-strength weld, containing hydrogen, takes place at significantly lower value of the plastic strain than that of steel VSt3sp. At that, content of $[\mathrm{H}]_{\mathrm{def}}$ at the moment of fracture for high-strength weld metal is noticeably lower than for steel VSt3sp. Fracture of VSt3sp steel specimen provokes formation of hydrogen trapped by plastic strain and its content makes $[\mathrm{H}]_{\mathrm{def}}=1.2 \mathrm{~cm}^{3} / 100 \mathrm{~g}$. At that, $0.65 \mathrm{~cm}^{3} / 100 \mathrm{~g}$ of hydrogen is contained in the dislocations (peak at $150{ }^{\circ} \mathrm{C}$ ) and $0.55 \mathrm{~cm}^{3} / 100 \mathrm{~g}$ is present in molecular form in the microvoids (peak at $\left.250{ }^{\circ} \mathrm{C}\right)[12]$.

Structure and properties of the plastically deformed steels are recovered by heating at (0.4$0.5) T_{\text {melt }}$ (recrystallization annealing). Heat treatment to indicated temperatures effects the dislocation structure [8] and can influence its interaction with the dissolved hydrogen. In this connection the investigations were carried out on effect of treatment temperature of the deformed weld metal on its interaction with dissolved hydrogen.

Single-run welds on steel VSt3sp, deposited by UONI-13/55 electrodes, which were stored after welding at $T=20-25{ }^{\circ} \mathrm{C}$ during one month, and then bending deformed by approximately $16 \%$, were used as metal specimens. Specimens of $15 \times 5 \times 1 \mathrm{~mm}$ size were cut out from weld metal upper layer. They were heat treated at 20-950 ${ }^{\circ} \mathrm{C}$ temperature range in argon media and then electrolytic hydrogenation was carried out

Table 2. Mechanical properties of materials studied

\begin{tabular}{||c|c|c|c|c|c|c||}
\hline \hline \multirow{2}{*}{ Material } & $\sigma_{0.2}, \mathrm{MPa}$ & $\sigma_{\mathrm{t}}, \mathrm{MPa}$ & $\delta, \%$ & $\psi, \%$ & {$[\mathrm{H}]_{\text {dif }}, \mathrm{cm}^{3} / 100 \mathrm{~g}$} & {$[\mathrm{H}]_{\text {def }}, \mathrm{cm}^{3} / 100 \mathrm{~g}$} \\
\hline \multirow{2}{*}{ Steel VSt3sp } & 270 & 420 & 33.4 & 54 & 0 & 0 \\
\cline { 2 - 8 } & 250 & 420 & 15.6 & 15 & 8.5 & 1.2 \\
\hline \multirow{2}{*}{ Weld metal (IP) } & 670 & 930 & 15.3 & 55 & 0 & 0 \\
\cline { 2 - 8 } & 720 & 830 & 0.7 & 1 & 8.0 & 0.15 \\
\hline
\end{tabular}




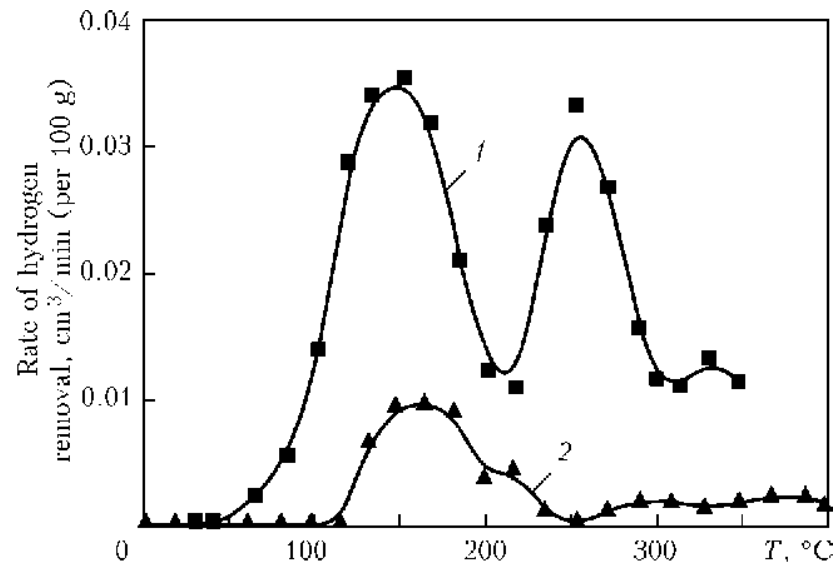

Figure 5. Spectrum of thermodesorption of residual hydrogen from specimens after fracture: 1 - steel VSt3sp, $[\mathrm{H}]_{\mathrm{def}}=1.2 \mathrm{~cm}^{3} / 100 \mathrm{~g} ; 2-$ IP weld metal, $[\mathrm{H}]_{\text {def }}=$ $=0.15 \mathrm{~cm}^{3} / 100 \mathrm{~g}$

based on procedure mentioned above. Content of $[\mathrm{H}]_{\text {dif }}$ at $T=20-25{ }^{\circ} \mathrm{C}$ was measured using chromatographic method after hydrogenation. TDA of $[\mathrm{H}]_{\text {res }}$ was carried out after $[\mathrm{H}]_{\text {dif }}$ desorption ending. Table 3 gives the experiment results. It can be seen from presented data that heat treatment of the specimens at $T>A_{3}\left(950{ }^{\circ} \mathrm{C}\right)$ and below $A_{1}$ including $550{ }^{\circ} \mathrm{C}$, removes the dislocation structure, capable to interact with the dissolved hydrogen due to reduction of the dislocation density, and, probably, formation of Cottrell clouds by nitrogen and carbon atoms, having stronger bonding energy than hydrogen. Capability of the dislocation structure to interact with hydrogen in the process of electrolytic saturation is still preserved in treatment at $400{ }^{\circ} \mathrm{C}$ and below. Thus, the heat treatment temperature, which provides change of effect of the dislocation structure on hydrogen absorption, agrees with the temperature of crystallization treatment of the deformed steel.

\section{Conclusions}

Interaction of the dissolved hydrogen with the dislocation structure, forming as a result of plastic strain of steels and welds, was determined in experimental way. Typical temperature of removal of the hydrogen fraction, bonded with dislocation fracture, is $100-200{ }^{\circ} \mathrm{C}$ with maximum rate of removal at $150-170{ }^{\circ} \mathrm{C}$.

Content of dislocation-trapped hydrogen in the metal is unsteady and reduce in dwell time at room temperature, that indicates reversible nature of dislocations as hydrogen traps.

Removal of hydrogen from crystalline lattice and dislocations is general process, characterizing by variable value of diffusion coefficient. The
Table 3. Effect of heat treatment of deformed weld metal (UONI-13/55) on electrolytic hydrogen saturation

\begin{tabular}{|c|c|c|c|c|}
\hline $\begin{array}{c}\text { Number } \\
\text { of expe- } \\
\text { riment }\end{array}$ & $\begin{array}{l}\text { Condition of } \\
\text { specimen }\end{array}$ & $\begin{array}{c}\text { Heat } \\
\text { treatment }{ }^{*},{ }^{\circ} \mathrm{C}\end{array}$ & $\begin{array}{l}{[\mathrm{H}]_{\text {dif }},} \\
\mathrm{ml} / 100 \mathrm{~g}\end{array}$ & $\begin{array}{l}{[\mathrm{H}]_{\text {dis }},} \\
\mathrm{ml} / 100 \mathrm{~g}\end{array}$ \\
\hline 1 & $\begin{array}{c}\begin{array}{c}\text { Deformation- } \\
\text { free }\end{array} \\
\end{array}$ & $\begin{array}{c}\text { Without } \\
\text { HT }\end{array}$ & $2.2-3.0$ & 0 \\
\hline 2 & $\begin{array}{c}16 \% \\
\text { deformed }\end{array}$ & 20 & $7.4-7.7$ & 0.2 \\
\hline 3 & Same & 950 & 4.2 & 0 \\
\hline 4 & $»$ & 850 & 2.3 & 0 \\
\hline 5 & $》$ & 700 & 4.3 & 0 \\
\hline 6 & $\gg$ & 550 & 8.4 & 0 \\
\hline 7 & $》$ & 400 & 7.0 & 0.2 \\
\hline
\end{tabular}

diffusion coefficient, which is determined by trapping of hydrogen with dislocation, is 3 orders lower than the coefficient of hydrogen diffusion in the crystalline lattice.

Value of plastic strain, which provides for fracture, reduces under effect of diffusible hydrogen with the increase of metal strength. At that, content of hydrogen trapped by dislocations at the moment of fracture also significantly reduces with rise of metal strength.

1. Geld, P.V., Ryabov, R.A. (1974) Hydrogen in metals and alloys. Moscow: Metallurgiya.

2. Geld, P.V., Ryabov, R.A., Kodes, E.S. (1979) Hydrogen and imperfections of metal structure. Moscow: Metallurgiya.

3. Novikov, I.I. (1975) Defects of crystalline structure of metals. Moscow: Metallurgiya.

4. Ivanova, V.S., Gorodienko, L.K., Geminov, V.N. et al. (1965) Role of dislocations in strengthening and fracture of metals. Ed. by V.S. Ivanova. Moscow: Nauka.

5. Gulyaev, A.P. (1978) Metals science. 5th ed. Moscow: Metallurgiya.

6. Kolachev, B.A. (1985) Hydrogen brittleness of metals. Moscow: Metallurgiya.

7. Maroeff, I., Olson, D.L., Eberhart, M. et al. (2002) Hydrogen trapping in ferritic steel weld metal. Int. Materials Rev., 47(4), 191-223.

8. Cotterill, P. (1963) Hydrogen embrittlement of metals. Successes of physics of metals. Vol. 9. Moscow: Metallurgizdat.

9. Pokhodnya, I.K., Yavdoshchin, I.R., Paltsevich, A.P. et al. (2004) Metallurgy of arc welding. Interaction of metals with gases. Kiev: Naukova Dumka.

10. Paltsevich, A.P. (1999) Chromatographic method for determination of hydrogen content in components of electrode coatings. Avtomatich. Svarka, 6, 45-48.

11. Choo, W.Y., Jai Yong Lee (1982) Thermal analysis of trapped hydrogen in pure iron. Metallurg. Transact. A, 13, 135-140.

12. Moreton, G., Coe, F.R., Boniszewski, T. (1971) Hydrogen movement in weld metal. Pt 1. Metal Construction and British Welding J., 3(5), 185-187.

Received 25.04.2014 